\title{
ANEMIA OF INFANCY FROM MATERNAL IRON DEFICIENCY IN PREGNANCY 1,2,3
}

\author{
BY MAURICE B. STRAUSS
}

(From the Thorndike Memorial Laboratory, the Second and Fourth Medical Services (Harvard), Boston City Hospital, and the Departments of Medicine and Tropical Medicine of the Harvard Medical School, Boston)

(Received for publication November 11, 1932)

During the progress of studies made upon anemia in pregnancy $(1,2,3$, $4,5,6)$, it was observed that no matter how anemic the mothers, their infants were always born with a normal amount of hemoglobin and a normal red blood cell count. It shortly became apparent, however, that after several months these infants born of anemic mothers developed pallor, which became most marked toward the end of the first year of life. Studies were therefore made to determine the nature of this condition, its prevention and treatment. The results presented here indicate that this anemia of infancy is the result of maternal iron deficiency during pregnancy, which may be prevented by supplying an adequate amount of iron to the pregnant mother, or when developed in the infant, may be treated successfully by iron.

The observations now reported were made only upon normal full-term infants. Critical examination of the mothers failed to reveal any abnormalities other than those attributable to hypochromic anemia and gastric secretory defects (6). Control observations were made upon the infants of entirely normal women who were studied throughout pregnancy. (See reference (5), Group I.) Observations made upon the infants of mothers suffering from pernicious anemia of pregnancy are not studied in detail in this report but will be referred to briefly.

Details as to methods employed in blood examination have been given (5). Routine examinations were made upon specimens obtained from a freely bleeding puncture of the infant's heel, and upon maternal blood withdrawn without stasis from the antecubital vein. The Sahli hemometer calibrated so that 100 per cent hemoglobin equals 15.6 grams per 100 cc. of blood was employed.

${ }^{1}$ This study was made possible through the cooperation of the visiting surgeons and house staff of the Obstetrical Service of the Boston City Hospital.

${ }_{2}$ The technical work on the blood was performed chiefly by Miss Margaret Evans and Miss Florence Kelley.

${ }^{3}$ The expenses of this investigation were defrayed in part by the J. K. Lilly gift to the Harvard Medical School, Boston. 
The infants generally were breast-fed for from 4 to 6 months and were then given cow's milk with cereals, cod liver oil, and orange juice. No differences of diet between the control infants and those of the anemic mothers were noted. All the anemic mothers not treated for anemia during pregnancy were treated with iron after delivery. No infants who presented any abnormalities or infections other than the mild acute upper respiratory type were studied. No difference in the frequency of "colds" was observed in the several groups. All the infants were well nourished, gained weight properly and appeared well except for pallor.

\section{OBSERVATIONS}

Examinations of the blood were made within 48 hours of birth upon 15 infants whose mothers exhibited less than 45 per cent hemoglobin at the time of delivery and upon 12 infants whose mothers presented more than 70 per cent hemoglobin (Chart $\mathrm{I}$ ). The average hemoglobin of the

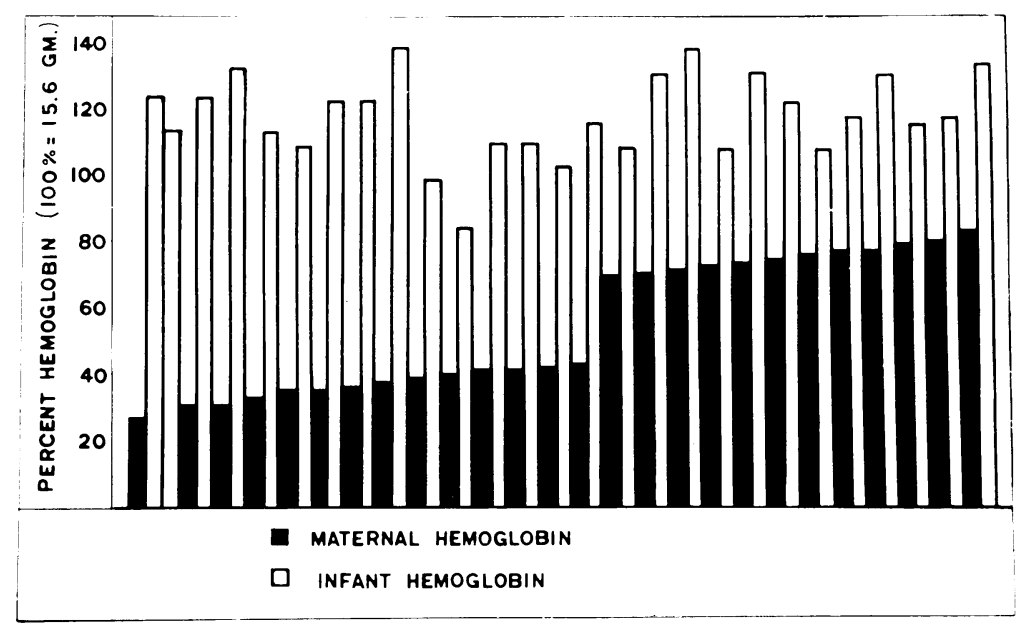

Chart I. Comparison of Maternal and Infant Hemoglobin in 14 ANemic ANd 12 Normal Mothers

first group of mothers was 36 per cent and of the second group 76 per cent. The anemia of the first group was of the hypochromic type and has been described previously $(1,6)$.

The infants born to these anemic mothers had on the average 116 per cent hemoglobin (standard deviation $=13.26$ per cent; probable error of mean $= \pm 9.25$ per cent), and those of the normal mothers 123 per cent (standard deviation $=10.58$ per cent; probable error of mean $= \pm 7.17$ per cent). The difference between the average hemoglobin of the two groups, 7 per cent, is less than the probable error of the means, 11.7 per cent, and hence of no significance. It is thus apparent that maternal 
anemia did not reduce the infants' hemoglobin. The average erythrocyte count of the infants of anemic mothers was 5,603,000 per cu. mm. and of the infants of normal mothers $5,498,000$ per cu. mm.

At birth the blood histologically showed no deviation from normal. Figure $1(a)$ and $(c)$ are photomicrographs of blood films from new-born infants of anemic mothers. Differential white blood cell counts were

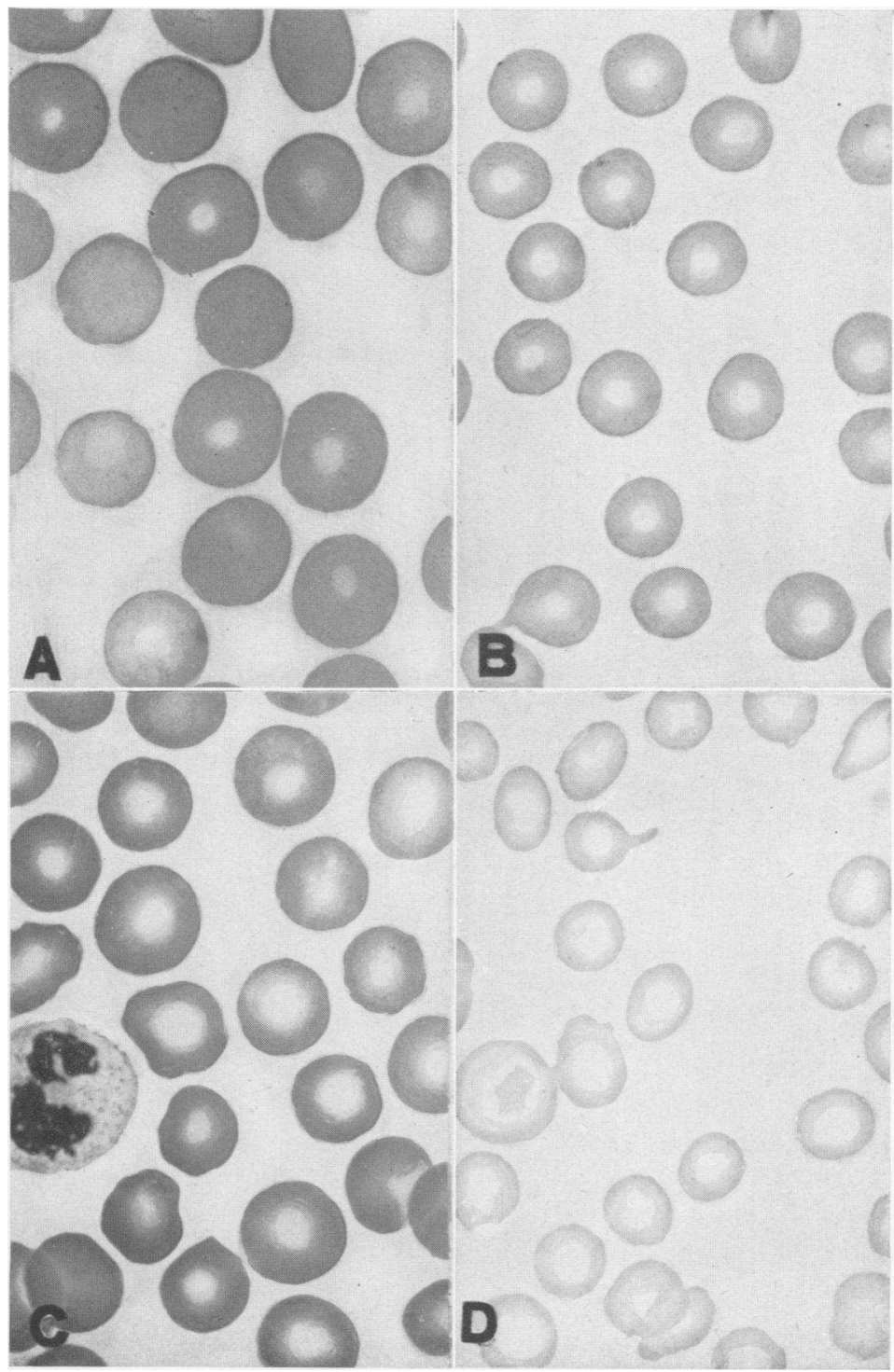

Fig. 1. (Magnification $\times 1256$.) Comparison of Blood Films at Birth and at One Year of Two Infants Born of Anemic Mothers $(A)$ and $(C)$ at birth $(B)$ and $(D)$ one year later from the same infants. 
normal for new-born infants. The total erythrocyte and leukocyte counts compare satisfactorily with the observations of Baty (7).

These data, then, indicate that the fetus is abte to draw upon the mother for all the blood-forming materials necessary for its own immediate requirements, irrespective of the condition of the maternal blood.

That a different state of affairs exists as far as storage material is concerned became evident when these infants were re-examined later on in their first year of life. Six of the infants born to anemic mothers and six born to normal mothers were re-examined about one year after birth (Chart II). In every case the infants born to normal mothers had 64 per

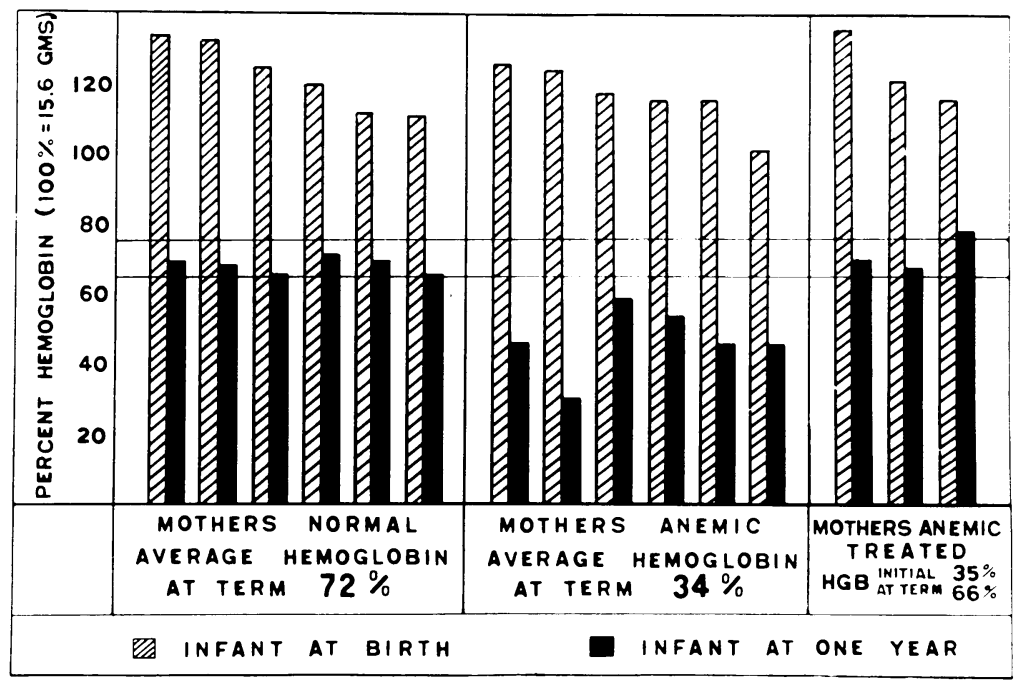

Chart II. Comparison of Hemoglobin at Birth and at One Year of Infants of Normal, Anemic, and Treated Anemic Mothers

The lines at 65 and 75 per cent represent the usual normal range at one year.

cent hemoglobin or over with an average of 67.1 per cent (standard deviation $=2.54$ per cent; probable error of mean $= \pm 1.86$ per cent). On the other hand, each of the six infants born to anemic mothers had less than 58 per cent hemoglobin with an average of 46 per cent (standard deviation $=8.7$ per cent; probable error of mean $= \pm 6.4$ per cent). The difference between the two averages, 21.1 per cent, is more than three times its probable error, 6.63 per cent, and hence significant. Five additional infants born of anemic mothers but who had not been examined at birth, were examined when 1 year old. Each one had less than 56 per cent hemoglobin with an average of 46.2 per cent. Comparing the hemoglobin of the 11 infants of anemic mothers with those of normal mothers, the difference between the means of the two groups is 21.1 per cent or almost four times its probable error, 5.54 per cent, and hence significant. 
In Figure $1(b)$ and $(d)$ are photomicrographs of the blood from the anemic infants at 1 year of age with the highest and lowest hemoglobin, namely 56 and 30 per cent. The figure also shows for comparison the blood of the same infants at birth (Fig. $1(a)$ and $(c)$ ). The obvious changes are representative of the entire group of anemic infants. At 12 months the red blood cells were small and poorly filled with hemoglobin. Aniso- and poikilocytosis varied from moderate to marked. The total number of erythrocytes varied from $4,440,000$ to $5,810,000$, averaging $5,040,000$ per cu. $\mathrm{mm}$. The number of blood platelets was usually normal,

TABLE 1

Total and differential leukocyte counts made upon six infants with anemia due to maternal iron deficiency

\begin{tabular}{r|c|c|c|c|c|c|c}
\hline \hline $\begin{array}{c}\text { Total } \\
\text { leukocytes } \\
\text { per cu.mm. }\end{array}$ & $\begin{array}{c}\text { Polynuclear } \\
\text { neutrophils }\end{array}$ & $\begin{array}{c}\text { Polynuclear } \\
\text { eosinophils }\end{array}$ & $\begin{array}{c}\text { Polynuclear } \\
\text { basophils }\end{array}$ & $\begin{array}{c}\text { Small } \\
\text { lymphocytes }\end{array}$ & $\begin{array}{c}\text { Large } \\
\text { bmphocytes }\end{array}$ & Monocytes & $\begin{array}{c}\text { Immatures } \\
\text { (lymphatic) }\end{array}$ \\
\cline { 2 - 7 } 8,000 & per cent & per cent & per cent & per cent & per cent & per cent & per cent \\
10,400 & 23.5 & 1.0 & 1.5 & 41.0 & 5.5 & 6.5 & 1.5 \\
14,850 & 17.5 & 4.5 & 1.5 & 52.5 & 6.0 & 11.5 & 2.0 \\
6,500 & 19.0 & 8.5 & 1.0 & 55.0 & 11.5 & 6.0 & 0.5 \\
10,250 & 51.0 & 1.0 & 0.5 & 61.0 & 7.0 & 10.5 & 1.0 \\
15,600 & 12.5 & 2.5 & 0.5 & 22.5 & 4.5 & 9.5 & 2.0 \\
\hline
\end{tabular}

but sometimes slightly increased or decreased. Total and differential white cell counts are given in Table 1.

The blood picture of these infants, then, is essentially that seen in any type of iron deficiency anemia.

From these data it might be inferred that an hereditary abnormality in blood formation exists in infants born to anemic mothers. That this is not the case is evident from the following observations: three pregnant women with severe hypochromic anemia (average hemoglobin 35 per cent) were treated with 6 grams of iron and ammonium citrate daily during the last 3 months of their pregnancies and at parturition their average hemoglobin was 66 per cent. Their infants presented normal amounts of hemoglobin, not only at birth but at the end of the first year of life (Chart II). It is obvious that iron therapy can not change an hereditary condition, but can make available an adequate amount of blood-building material to supply a deficiency of fetal storage. These data indicate that infants born to mothers suffering from iron deficiency, although exhibiting at birth a normal blood picture, are unable to maintain a normal hemoglobin level during the first year of life.

To corroborate further the theory that iron deficiency causes this anemia of infancy, six anemic infants were given daily in 3 divided doses 1 gram of iron and ammonium citrate in their milk. No change was 
made in diet or other routine measures. The results of this therapy are shown in Table 2 . In every case prompt hemoglobin regeneration took

TABLE 2

Response to the administration of 1 gram of iron and ammonium citrate daily

\begin{tabular}{c|c|c|c|c}
\hline \hline \multicolumn{2}{c|}{ Before treatment } & \multicolumn{2}{|c}{ After treatment } & $\begin{array}{c}\text { Number of } \\
\text { days treated }\end{array}$ \\
\cline { 2 - 4 } Red blood cells & Hemoglobin & Red blood cells & Hemoglobin & \\
\hline millions & per cent & millions & per cent & \\
4.940 & 43 & 5.310 & 70 & 76 \\
5.440 & 45 & 7.070 & 76 & 28 \\
4.680 & 45 & 5.630 & 63 & 70 \\
4.980 & 45 & 6.110 & 72 & 42 \\
5.470 & 47 & 6.980 & 70 & 19 \\
7.500 & 56 & 6.380 & 75 & \\
\hline
\end{tabular}

place, the normal level being reached usually within a month. Coincidently, but more slowly, the microscopic appearance of the red blood cells returned to normal.

Thus the anemia of infancy developing in the babies of anemic mothers, deficient in iron, is remediable by administering iron orally. A deficiency of this element is therefore the probable cause of this form of anemia.

\section{DISCUSSION}

Anemia in infancy not due to associated disease often has been considered dependent upon congenital abnormality of blood formation or defective postnatal nutrition.

It is apparent that the anemia of infancy now described is not due to congenital abnormal blood formation since these babies exhibited normal blood at birth and when the mothers were adequately supplied with iron the anemia was prevented from developing. Were the course of events due to a congenital defect for which the germ plasm were responsible, the result could not, in all probability, have been modified.

That defective postnatal nutrition is involved seems unlikely since observations made at intervals during the first year of life suggest that this anemia appears before the sixth month, at a time when the infant's diet is ordinarily restricted to milk and vitamin supplements. Milk itself contains so little iron that it appears improbable that a quantitative deficiency of iron in the breast milk of the anemic mothers should be the cause of the trouble. The mothers not given iron during pregnancy were treated with this element after delivery while they were nursing. Furthermore two bottle-fed infants of anemic mothers developed the same type anemia.

It has been demonstrated by numerous investigators $(8,9,10,11)$ that a diet deficient in iron, fed to animals, results in anemia in the off- 
spring analogous to the anemia of infancy now described. In order to understand the mechanism involved, it is necessary to appreciate the fact that normal infants or animals at birth possess five times as much iron per gram of body weight as do adults $(12,13)$. This iron is stored chiefly in the liver and, as growth proceeds, is drawn upon to supply the requirement of the blood for iron since few mammals obtain iron from their food until after weaning. It is significant that guinea pigs, which eat green food from birth, from which they obtain iron, do not possess nearly so great a store of iron in reserve in their livers as do most animals. Bunge (14) first pointed out that anemia is likely to develop if a diet poor in iron (i.e., milk) is continued after the exhaustion of the iron reserves of the body. A diet deficient in iron can, on the other hand, hardly produce effects as long as a reserve supply is present. But when parents are deprived of iron, as were the animals just mentioned and the mothers now described, there is reason to believe that new-born infants or animals will lack this store of iron, so that when they are placed on a diet deficient in iron, anemia will develop. Until quantitative chemical studies can be made of the livers of suitable infants, this explanation must remain in the realm of hypothesis.

In human beings, no study similar to the present one has been found recorded in the literature. Mackay (15) studied a number of infants whose mothers' hemoglobin ranged between 7.45 and 9.66 grams in comparison with those whose mothers exhibited hemoglobins of more than 9.79 grams. She found that the offspring of the latter possessed about 0.7 gram more hemoglobin in the first year of life than did those of the slightly anemic mothers. Maurer, Greengard and Kluver (16) made somewhat similar observations, but in no instance did the mothers they describe have a severe grade of anemia. Parsons (17) has recently observed what he believes to be congenital anemia in the babies of mothers who had consumed deficient diets, but this form of anemia is probably identical with the condition described in this report.

Certain facts relative to the blood of normal infants are of interest. The infants of the normal women exhibited on the average 10.47 grams (67 per cent Sahli) hemoglobin when 1 year old as contrasted with 13.53 grams ( 80 per cent Newcomer) observed by Baty (7) and 8.97 grams (65 per cent Haldane) observed by Mackay (15). Baty's patients came from a somewhat higher social and economic class and Mackay's from a somewhat lower one. It is suggested therefore that the nutritional levels of the mothers are responsible for the differences observed in "normal" infants.

These observations explain why some infants given defective diets develop so-called nutritional anemia whereas others on identical diets do not. It is probable, since large differences in the amount of iron in storage occur in infants born of women markedly deficient in iron, that 
minor grades of this condition also result in the storage of deficient amounts of iron by the fetus. Anemia then develops in the child only if it is given a diet deficient in iron for too long a period of time.

In contrast to these observations in infants born to mothers suffering from hypochromic anemia, it is interesting to record that a form of anemia has been observed which is characterized by a decrease in the number of erythrocytes relatively greater than that in the amount of hemoglobin, so that high color indices resulted. This form was detected in two infants born of women ill with so-called "pernicious (macrocytic) anemia of pregnancy." The reduction in erythrocytes occurred earlier (2 to 4 months) and disappeared without the necessity of therapy. In the light of previous observations on macrocytic anemia (18) it is reasonable to believe that these infants lacked material effective in preventing pernicious anemia, perhaps vitamin $\mathrm{B}_{2}$. Ultimately the lack was corrected by the accumulation of this material in milk which is rich in vitamin $B_{2}$.

\section{CONCLUSIONS}

1. Infants born to women suffering from hypochromic anemia exhibit a normal blood picture at birth but develop moderate to severe degrees of anemia during the first year of life.

2. This form of anemia may be prevented by administering iron to the mothers during pregnancy or may be corrected by administering iron to the anemic infants.

3. It is believed that this form of anemia is due to deficient storage of iron by the fetus dependent upon a deficient supply of this element in the mother.

\section{BIBLIOGRAPHY}

1. Strauss, M. B., Am. J. II. Sc., 1930, clxxx, 818. Chlorotic Anemia of Pregnancy. A Report of Three Cases.

2. Strauss, M. B., and Castle, II. B., Lancet, 1932, i, 1198. The Aetiology and Treatment of Anaemia in Pregnancy.

3. Strauss, M. B., J. Clin. Invest., 1932, xi, 809. Observations on the Etiology and Treatment of Anemia in Pregnancy.

4. Strauss, M. B., and Castle, W. B., Am. J. M. Sc., 1932, clxxxir, 65. Studies of Anemia in Pregnancy. I. Gastric Secretion in Pregnancy and the Puerperium.

5. Strauss, M. B., and Castle, IV. B., Am. J. M. Sc., 1932, clxxxiv, 663. Studies of Anemia in Pregnancy. II. The Relationship of Dietary Deficiency and Gastric Secretion to Blood Formation During Pregnancy.

6. Strauss, M. B., and Castle, W. B., Am. J. M. Sc., In press. Studies of Anemia in Pregnancy. III. The Etiologic Relationship of Gastric Secretory Defects and Dietary Deficiency to the Hypochromic and Macrocytic (Pernicious) Anemias of Pregnancy, and the Treatment of These Conditions.

7. Baty, J. M., New England J. Med., 1930, cciii, 319, and personal communication. Anemia in Infants and Children. 
8. Schmidt, M. B., Verh. d. deutsch. path. Gesellsch., 1912, xv, 91. Ueber die Organe des Eisenstoffwechsels und die Blutbildung bei Eisenmangel.

9. Happ, W. M., Bull. Johns Hopkins Hosp., 1922, xxxiii, 163. Occurrence of Anemia in Rats on Deficient Diets.

10. Scott, J. M. D., Biochem. J., 1923, xvii, 166. Studies in Anaemia. II. Comparison of Methods of Producing an Anaemia Characterised by Low Colour Index.

11. Waddell, J., Steenbock, H., Elvehjem, C. A., and Hart, E. B., J. Biol. Chem., 1928, lxxvii, 769. Iron in Nutrition. V. The Availability of the Rat for Studies in Anemia.

12. Bunge, G., Ztschr. f. physiol. Chem., 1892, xvi, 173. Weitere Untersuchungen über die Aufnahme des Eisens in den Organismus des Säuglings.

13. Bunge, G., Ztschr. f. physiol. Chem., 1892, xvii, 63. Ueber die Aufnahme des Eisens in den Organismus des Säuglings (Nachtrag).

14. Bunge, G., Textbook of Physiological and Pathological Chemistry. P. Blakiston's Son \& Co., Philadelphia, 1902.

15. Mackay, H. M. M., Nutritional Anemia in Infancy. Special Report No. 157. Medical Research Council, London, 1931.

16. Maurer, S., Greengard, J., and Kluver, C., J.A.M.A., 1932, xcviii, 1069. The Value of Liver Extract and Iron in the Anemia of Young Infants.

17. Parsons, L. G., Acta pediat., 1932, xiii, 378. Congenital Anaemia.

18. Strauss, M. B., and Castle, W. B., New England J. Med., 1932, 1v, 207, and Lancet, 1932, ii, 111. The Nature of the Extrinsic Factor of the Deficiency State in Pernicious Anemia and in Related Macrocytic Anemias. 